\title{
Psychological Endurance Hypothesis for Uncertain Decision and Its Application in Supply Chain Information Sharing
}

\author{
Xirong Gao, Ying Shi, Jianguang Zhang*, Yang Luo \\ School of Economics \& Management, Chongqing University of Posts and Telecommunications, Chongqing, China \\ Email: *zhangjg@cqupt.edu.cn
}

How to cite this paper: Gao, X. R., Shi, Y., Zhang, J. G., \& Luo, Y. (2017). Psychological Endurance Hypothesis for Uncertain Decision and Its Application in Supply Chain Information Sharing. Journal of Financial Risk Management, 6, 210-229. https://doi.org/10.4236/jfrm.2017.62016

Received: May 30, 2017

Accepted: June 25, 2017

Published: June 28, 2017

Copyright $\odot 2017$ by authors and Scientific Research Publishing Inc. This work is licensed under the Creative Commons Attribution International License (CC BY 4.0).

http://creativecommons.org/licenses/by/4.0/ (c) (i) Open Access

\begin{abstract}
This paper aims to present a new hypothesis to understand better decisions with uncertainties, and to explore as well its application in improving supply chain information sharing. From the observation that real investment decision behaviors generally imply that investors' mental states tend to experience subtle changes with increasing the amount of investments, the psychological endurance hypothesis and the corresponding utility function are constructed. The hypothesis embraces the income-cost ratio into the set of constraints of the value of an investment, which emphasizes the decisive role of investment return rate or profit rate, and then innovatively introduces the concept of critical point of psychological endurance from which it is found that the investment behaviors demonstrate completely different characteristics on the left and right side of this critical point, and that investors' investing willingness could be raised through exercising their psychological endurance to move outward the locations of their critical points of psychological endurance. Making further use of the hypothesis produces the shorter-board optimization model of supply chain information sharing with decision variable of the value index of information sharing. This model reveals that enterprise's value index of information sharing has a positive relationship with the success rate of information sharing, but a negative one with the information-sharing cost elasticity of psychological vulnerability, the social risk level, and the cost of information sharing. And the model also suggests that the overall information sharing of a supply chain could be eventually achieved by ever increasing the shorter-board enterprise's value index of information-sharing.
\end{abstract}

\section{Keywords}

Psychological Endurance, Uncertainty, Decision Analysis, Supply Chain, Information Sharing 


\section{Introduction}

Our world is full of numerous uncertainties. The fears of and worries about the uncertainties of future consequences have been always haunting people's decision-makings. When facing the uncertainties, decision-makers appear to be making bets in casinos and what they could do is just to wait for the judgment of the God. If so, how high is the stake that a decision-maker is likely to choose to bet on the uncertainty? Naturally, the size of the stake is firstly determined by his/her money to gamble with or wealth endowment. In general, the more the gamble-money or wealth a decision-maker has, the higher the stake he/she makes. However, when decision-makers have the same amount of gamblemoney or wealth, the real sizes of the stakes they made, under most circumstances, may be very different. This implies that, in addition to wealth endowment, there still exist more and deep-rooted factors that influence people's decision-making behavior in the context of uncertainties.

In order to explore the profound factors impacting decision-making with uncertainty, von Neumann and Morgenstern (1944) put forward the expected utility theory with the argument that people would decide the size of a stake in accordance with the expected utility level of a bet. However, the expected utility is the probability-weighted average of the results of success or failure, the fatal defect of which is that it fails to take into consideration the spiritual pressure incurred to a decision-maker following a lost bet. In fact, if the spiritual pressure resulting from a lost bet is big enough, the bet should not be attractive anymore no matter how high the expected utility is. In other words, giving the precondition that probabilities of win and loss remain the same, people's psychology will subtly change with increasing the size of a stake, and when such change has reached a critical value, it will result in decreasing the utility in absolute term, instead of the unceasing utility-increasing based on the expected utility theory (despite the slowdown increasing rate under the circumstance of risk-avoiding).

The perplexing experienced by individual enterprises facing decision-related uncertainties is very likely to be amplified substantially in the multiple decision-makings of participants in a supply chain. The cause of the amplification, to a large extent, comes from the information asymmetry among supply chain members. In order to lower the overall uncertainty level of the decisions of supply chain team members and to promote and obtain the synergistic effect of the whole supply chain system, the priority effort should be to raise the level of information sharing among the chain members. Only through effective and efficient information sharing can the members in the chain be integrated into a commercially synergistic team and then to participate into market competitions as a whole unity. However, the information sharing of supply chain has been remaining an unresolved problem in both theoretical researches and practices. The fundamental obstacle among others is the interest conflict between individualistic firms and the supply chain as a group. If the obstacles are to be effectively weakened or eliminated, a valid mechanism must be formulated to balance the interests of both individual firms and the supply chain as a whole, in which 
the members in the chain are guided into a positive feedback cycle of information sharing and the magnitude of information sharing is to be strengthened continuously till realizing the objective of integrating completely all chain enterprises.

Based on the observations that investors' mental states usually experience subtle changes with increasing the amount of investments when making decisions under uncertain situations, we have introduced innovatively the concept of psychological endurance, and from which we have constructed an analytical framework for uncertain decisions and have tried to apply the framework into improving the information sharing of supply chain. The rest of this paper is structured as: Section 2 is literature review; Section 3 introduces the psychological endurance hypothesis; Section 4 discusses the decision utility function based on psychological endurance; Section 5 constructs the applying supply chain information sharing model of the decision utility function based on psychological endurance; and Section 6 summarizes the conclusions and implications.

\section{Literature Review}

\subsection{The Theories Related to Uncertain Decisions}

The theories regarding the researches of uncertain decisions may be divided into types: the rational decision-making approach and the limited-rationality decision-making approach. The former believes that decision-makers are absolutely rational with the typical representatives of the expected value theory and the expected utility theory, whereas the latter argues that decision-makers exercise limited rationality and the prospect theory is a typical representative of this approach.

The expected value theory is the earliest about decisions under uncertainty, which states that people make decisions according to the expected value (referring to formula (1)).

$$
E V=\sum P_{i} X_{i}=P_{1} x_{1}+P_{2} x_{2}+\cdots+P_{n} x_{n}
$$

In formula (1) $E V$ is the mathematic expected value, $X_{i}$ denotes the value of result $i, P_{i}$ is the probability of the occurrence of result $i$.

But, as put by the St Petersburg Paradox of Nicholas Bernoulli in the year 1713, people's real decision behaviors do not follow what the expected value theory predicts. So in 1738 Daniel Bernoulli proposed the conception of utility function. And later von Neumann and Morgenstern (1944) formally put forward the expected utility theory, declaring that the basis of decisions under uncertainty is the principle of utility maximization instead of expected-value maximization. The formula to calculate the expected utility is:

$$
U(X)=\sum P_{i} u\left(X_{i}\right)=P_{1} u\left(x_{1}\right)+P_{2} u\left(x_{2}\right)+\cdots+P_{n} u\left(x_{n}\right)
$$

where $x_{i}$ denotes the final possible currency-denominated revenue, $P_{i}$ represents the probability of $x_{i}$, and $u\left(x_{i}\right)$ is the utility brought about by $x_{i}$. As a matter of fact, any decision with risks can be abstracted as an investment consisting of two outcomes: success or failure. If we assume the cost of invest- 
ment as $c$, the expected income as $r$, and the success probability as $p$, then the decision scenario facing an investor could be demonstrated by Figure 1.

In Figure 1 the expected revenue of the investment is $r p$ and the expected profit is $(r p-c)$. In line with the expectation utility theory, if the expected profit is not negative, that is, the expected income per unit cost $r p / c \geq 1$, the investor's investment is rational. And the higher the expected profit (representing final level of wealth), the bigger the value (i.e. utility) of the investment, but the marginal utility of the expected profit is decreasing.

The expected utility theory was developed upon four strict assumptions: completeness, transitivity, continuity and independence, but it was found that real decision behaviors did not conform completely with these assumptions, among which the most famous refutes are the Allais paradox and the Ellesberg paradox. The Allais paradox argued that people would overemphasize the outcomes of certainty in their decisions and thus they did not depend on the expected utility to make decisions with risks. Going farther, the Ellesberg paradox stressed that people's investment preferences did not follow the expected utility theory. With regard to the defect of the expected utility, Simon (1956) came up with the viewpoint of "limited rationality", which argued that since people possessed only limited cognitive capabilities under uncertain circumstances, it was impossible for them to predict completely accurately future outcomes, that people were not able to behave in a completely rational mode, and that they could only rely on limited rationality to avoid the risks of uncertainties.

On the basis of Simon's limited rationality, Kahneman and Tversky (1979) presented the prospect theory. It improved the expected utility in two aspects: one is the introduction of a subjective assessment scale, wealth reference point, which uses the change of wealth (the difference between the final wealth level and the wealth reference point), instead of the absolute value of wealth, to calculate the utility, and the other is differentiating the decisions under optimistic prospect from those under pessimistic prospect, pointing out that people were risk-aversive for the investments in the range of profit-making and risk- preferring for the investments in the range of loss-making (Figure 2). Later on, Tversky and Kahneman (1992) further proposed the accumulative prospect theory to explain the stochastic dominance, which successor researchers also have endeavored to improve. Wu \& Gonzalez (1996) and Cabantous \& Cedric (2004), for example, respectively added time variable and information quality into the analyses of the accumulative prospect theory.

The researches on decisions with limited rationality were mainly undertaken from the psychological perspective, such as the regret theory of Bell (1985), the

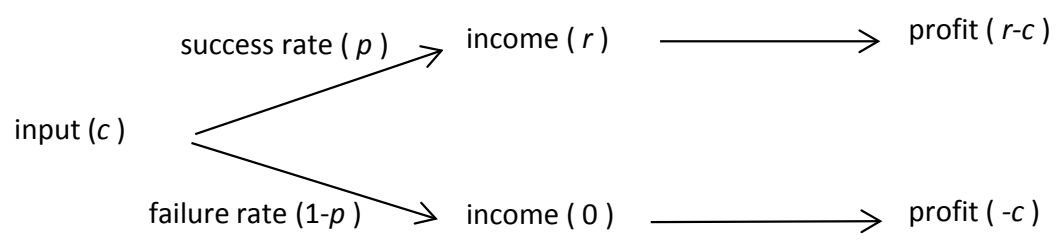

Figure 1. Cost and income relationship faced by an investor. 


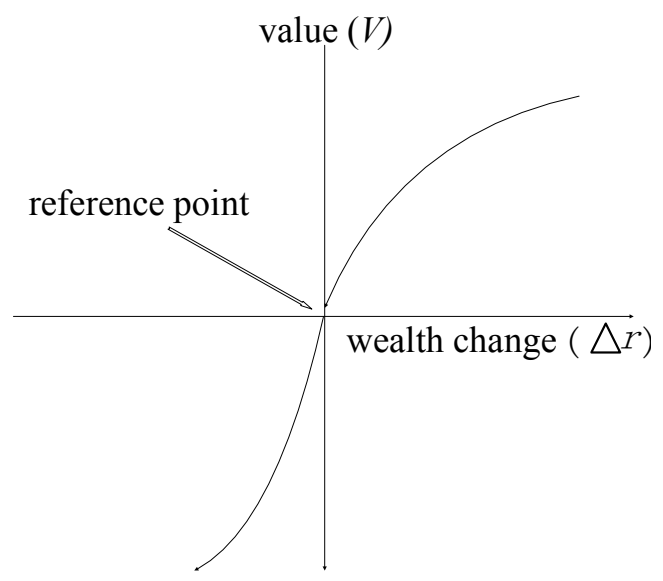

Figure 2. Value function for prospect theory.

disappointment theory of Loomes \& Sugden (1986), the emotion decision theory of Mellers (2000) and so on. In China, most of the studies of this approach concentrated on the impacts of moods on decisions, Xiao (2011), for instance, explored the influences of individuals' moods on decision behaviors under uncertainty, and Wang, Lu and Shen together (2013) studied the impacts on uncertain decisions of the magnitude of emotion awakening considering the popular preference-reversal phenomena in real life.

\subsection{Relevant Models of Supply Chain Information Sharing}

Current inquiries into supply chain information sharing generally suppose that the objective of nod enterprises is to maximize their own profits, and the focus is put on what models promote the forming and effecting of supply chain information sharing. Typical of these studies are flexibility contract, two-stage multiple-task principal-agent model, VMI cost-profit analysis, simulation model, game theory model, and the value model of demand information sharing and the like.

Chen and Miao (2010) researched the incentives to information sharing subject to the constraints of flexible contracts of supply chain, and explored the benefit allocation and coordination mechanism by considering the interest requirements of individual enterprises in the supply chain. Ma, Zhang, and Tian (2001) utilized two-stage multiple-task principal-agent model to investigate the optimal incentives from the core enterprise of supply chain to its suppliers for their supplying and sharing activities of information, and to explain the continuously improving processes of the partnerships in the chain. Sun and Liu (2013) analyzed the differences, under perfect competition, between the costs and profits under cooperative vendor managed inventory (VMI) and those of traditional inventory management, and illustrated how to raise information sharing by organizational information treatment capabilities. Ge et al. (2004) established a simulation model of multi-level supply chain information sharing to investigate how to increase the efficiency of supply chain. Lin and Tsao (2006) used CRP (continuous replenishment planning) and VMI as representative 
supply chain modes to simulate through computer and found that the inventory could be efficiently lowered and thus raise the outgoing efficiency. Zhang and Zhou (2004) took manufacturer as one player of a game, and the distributors and suppliers together as another player of the game, to study the causes of noncooperation in supply chain information sharing and the possibility of cooperation. The typical representatives of game-theory-oriented researchers are Zhang (2002) and Mishra et al. (2007). Ye, Chen and Lin (2012) built a decision model based on demand information sharing by use of condition value-at-risk $(\mathrm{CVaR})$ under the condition of random demand, and emphatically analyzed the magnitude of risk-avoiding of retailers and the impacts of uncertain demand information on both the individual decision-makers and the overall value of information sharing of supply chain.

Mukhopadhyay, Yue and Zhu (2011), Zhang \& Zhou (2004), and Zhou \& Ma (2010) all pointed out that the realization of the value of supply chain information sharing was restricted by the uncertainties from customer demand and market environments, which indicates that supply chain information sharing is a decision behavior under risks.

The literatures up to now exhibit the drawbacks of existent studies in three aspects: the first is inadequate consideration of the risks under the principle of profit-maximization decision regarding information sharing; the second, the concern is not enough over the impact of psychological factors on information sharing decisions; thirdly, they failed to consider the iterative improvement of supply chain information sharing level from the angle of raising the willingness to share information of the shorter-board enterprises in supply-chain bucket.

The template is used to format your paper and style the text. All margins, column widths, line spaces, and text fonts are prescribed; please do not alter them. You may note peculiarities. For example, the head margin in this template measures proportionately more than is customary. This measurement and others are deliberate, using specifications that anticipate your paper as one part of the entire journals, and not as an independent document. Please do not revise any of the current designations.

\section{The Psychological Endurance Hypothesis}

\subsection{The Importance of the Income per Unit of Cost}

The laws of capital market tell us that investors are concerned more with the relative earning (i.e. the rate of return on investment or the rewarding amount per unit of investment), exactly the same as profit rate, than with the absolute earning (the final wealth level). In Figure 1 the expected profit rate is $\left(r_{j} p_{j}-c_{j}\right) / c_{j}$ or $\left(r_{j} p_{j}^{\prime} c_{j}-1\right)$, which denotes that the decision variable that really influences enterprise's sharing of its information is the expected income per unit of cost $r_{j} p_{j} / c_{j}$ (or called expected income-cost ratio) rather than the absolute value of expected profit $\left(r_{j} p_{j}-c_{j}\right)$ (or called the difference between expected income and cost). To put it in another way, giving the same level of risk, the value for investor to obtain rises as the expected income-cost ratio increases, unlike the beliefs of the 
expectation utility theory and the prospect theory that the investor's would-be value goes up as increases the difference between the expected income and the cost of an investment.

\subsection{The Psychological Effect of the Risk of Absolute Loss}

Psychology knowledge lets us know that, given the same ratio of expected income-cost, the mental states of investors change subtly when the absolute value of the expected income (or cost) changes. Let's try, for instance, to fix the ratio of the expected income-cost at 1.2 and to set the success rate of investment at $60 \%$ (the corresponding expected profit rate is $20 \%$ ), then we examine the different mental statuses when the investment has "low" and "high" absolute levels of $\left(r_{p}\right.$ $\left.c_{j}\right)$ as follows.

Case one: assigning $\left(r_{p} c_{j}\right)$ "low" value as $(\$ 10, \$ 5)$, if successful (success probability $p_{j}$ equals $60 \%$ ), the income is 10 dollars and the cost 5 dollars, the profit is 5 dollars and the profit rate is $100 \%$; if failed (failure probability $\left(1-p_{j}\right)$ is $40 \%$ ), the income is 0 dollars and the cost 5 dollars, the profit is -5 dollars and the profit rate is $-100 \%$. In such a case, although the risk of failure amounts to $40 \%$, the investor can endure psychologically as the absolute loss is not big (only 5 dollars), and the investor will choose to invest considering the positive expected profit rate $(20 \%)$.

Case two: assigning $\left(r_{p} c_{j}\right)$ "high" value as $\left(\$ 10^{10}, \$ 5 \times 10^{9}\right)$, if successful (success probability $p_{j}$ equals $60 \%$ ), the income is 10 billion dollars and the cost 5 billion dollars, the profit is 5 billion dollars and the profit rate is $100 \%$; if failed (failure probability $\left(1-p_{j}\right.$ ) is $40 \%$ ), the income is 0 dollars and the cost 5 billion dollars, the profit is -5 billion dollars and the profit rate is $-100 \%$, the same as in Case one. However, in this case, the same $40 \%$ of risk of failure indicates a likely absolute loss of 5 billion dollars, which is too big for the investor to endure psychologically. Thus, in spite of the same expected profit rate as that in Case one, the investor will choose not to invest for safety.

The two cases can be intuitively displayed by Figure 3 .

\subsection{The Critical Point of Psychological Endurance under Uncertainty}

By fixing the risk level $(p)$ and the income-cost ratio $(r / c)$, we can examine

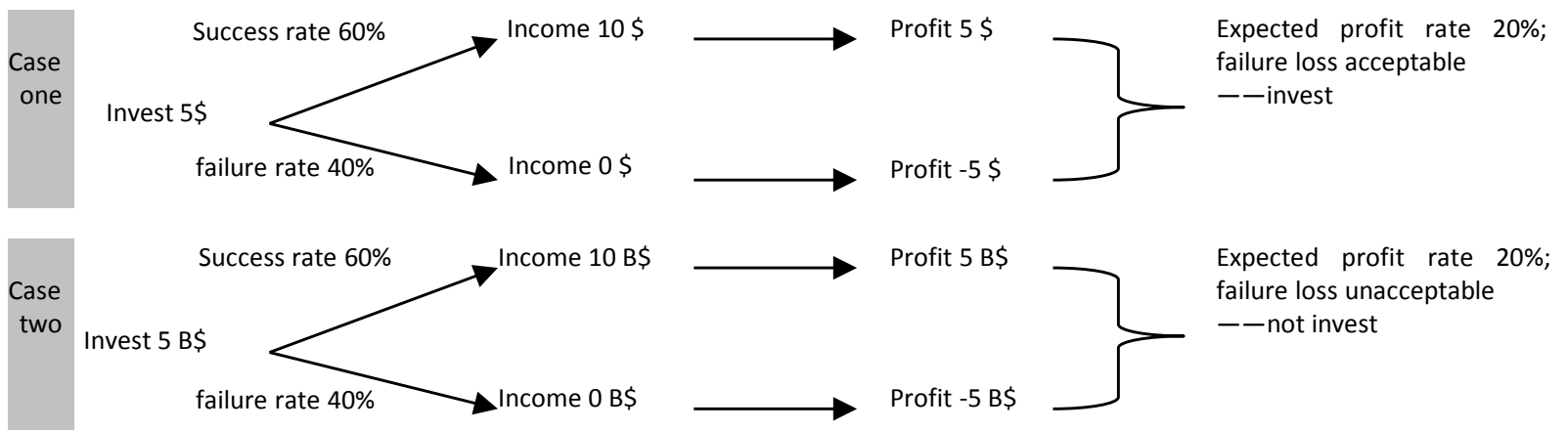

Figure 3. Psychological effects on investor of the absolute loss risk. 
specifically the relationship between investor's psychological value (i.e. utility of investment $u$ ) and absolute cost $(c)$ or absolute income $(r)^{1}$.

Giving the risk level $(p)$ and the income-cost ratio $(r / c)$, the mental states of investors will change with changes in the expected absolute value of income (or cost). Generally, there exists a critical point of psychological endurance in the mind of an investor, which may be denoted by a specific absolute income level $r^{*}$. The critical point of psychological endurance could be interpreted as the maximum tolerable investment loss resulting from uncertain investments, below which the investor's investing willingness does not weaken, holding constant the risk level and the income-cost ratio. Or to put it in another way, under the condition of given risk level and the income-cost ratio, the value of investment increases as the expected income level (or cost level) goes up, but when the expected income surpasses the critical point $r^{*}$, the value of investment decreases as the expected income level (or cost level) goes up.

\subsection{The Construction of Psychological Endurance Hypothesis}

Based upon the afore-mentioned psychological effect concerning investment decisions with risks, we have constructed the model of psychological endurance as shown in Figure 4.

Figure 4 shows that, when fixing the risk level and the income-cost ratio, the value of investment manifests a two-phase feature. In phase one, the expected income lies on the left side of critical point $r^{*}$, the value of investment demonstrates features similar to those of the expected utility theory, that is, the value of investment increases in decelerating way as the expected income level (or cost level) goes up. In phase two, the expected income lies on the right side of critical point $r^{*}$, the value of investment exhibits features completely different from those of the expected utility theory, that is to say, the value of investment decreases in decelerating way as the expected income level (or cost level) rises. One possible explanation of the right-side phenomenon is: the likely absolute loss

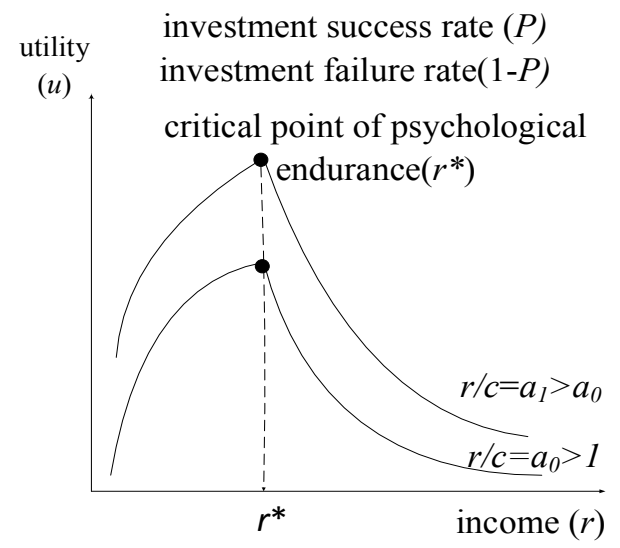

Figure 4. Psychological endurance hypothesis and the value of investment.

${ }^{1}$ Giving the income-cost ratio $(r / c)$, both income and cost change in the same proportional mode, so under such circumstance to examine the absolute income level $r$ or absolute cost level $c$ means the same. 
(the cost of investment) resulting from failure investment has surpassed the tolerable psychological capacity, which results in the going down of investing willingness. The willingness falls most remarkably in the close vicinity of the critical point and then goes down in a gradually slower pace possibly due to adaptation or numbness.

\subsection{The Visualized Interpretation of the Psychological Endurance Hypothesis}

The points of psychological endurance hypothesis could be visualized as walking above the ground. Imagine a scenario in which someone walks from the start of a footpath of 1-meter width and 100-meter length. If the footpath is on the ground, the walking is steady and safe and nearly anyone is able to finish it without any psychological burden. However, if the footpath were raised to 1 meter above the ground, then people may be able to finish the walking somewhat worryingly; if the footpath were further raised to 10 meter above the ground, people may very likely feel panic and dare not to start walking, and the walking in such a situation has become a risky adventure. It could be forecasted that although theoretically the risk of falling from the footpath does not change as the raised height keeps increasing, the changing external environment will create high altitude horror for the persons to walk, and because of fearing that they cannot tolerate the severe consequence of falling from the footpath, their mental endurances are gradually declining till they finally give up the walking (Figure 5). Investing is actually similar to the walking above the ground in that the investor's psychology will change subtly when increasing the stake of an investment.
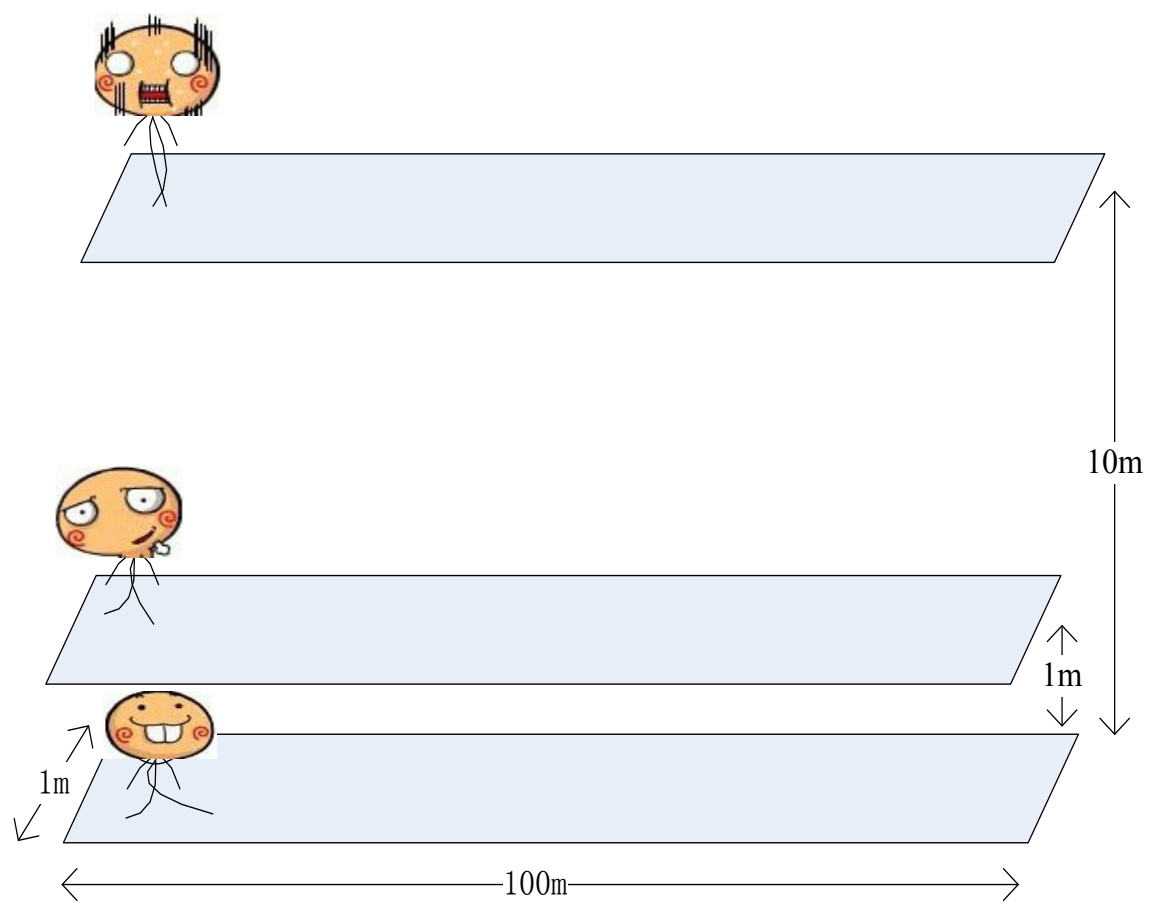

Figure 5. Walking in the air: visualizing psychological endurance hypothesis. 


\subsection{The Theoretical Value of the Psychological Endurance Hypothesis}

The theoretical contributions of the psychological endurance hypothesis are two: one is the introduction of the income-cost ratio into the constraints of investment value, stressing the decisive role of return rate of investment or profit rate, and the other is the conception that investment value changes with the change of investor's psychological endurance and the corresponding introduction of the critical point of psychological endurance, revealing that the investment behaviors on the left and right side of the critical point demonstrate completely opposite attributes. Table 1 summarizes the comparisons and contrasts of the psychological endurance hypothesis versus the expected utility theory and the prospect theory.

\section{The Decision Utility Function Based on the Psychological Endurance Hypothesis}

\subsection{The Construction of Decision Utility Function of Psychological Endurance Hypothesis}

On the base of the utility curve illustrated in Figure 4, the mathematical expression of the utility function can be constructed as in formula (3).

$$
U(c, r, p)= \begin{cases}(r / c)^{p \ln r} & r \leq r^{*} \\ (r / c)^{p\left(r^{*} / r\right) \ln r^{*}} & r>r^{*}\end{cases}
$$

In the above, $c$ is the cost of investment, $r$ is the expected income from investment, $p$ denotes the probability of investment success, and $r^{*}$ represents the critical point of psychological endurance. It should be noted that the critical point of psychological endurance $r^{*}$ is an individually varying subjective value because different individuals have different subjective perceptions of the same risk.

\subsection{The Partial Effect Analysis of the Utility Function of the Psychological Endurance Hypothesis}

By assigning the condition of $r / c=a_{0}$ to formula (3), we get formula (4).

Table 1. Psychological endurance hypothesis vs. the expected utility theory and the prospect theory.

1. The reference base is final wealth, and people make investing decisions
according to the expected utility value of the final wealth of an investment;
utility theory $\begin{aligned} & \text { 2. The utility increases with the increase of final wealth and the marginal } \\ & \text { utility is gradually decreasing. } \\ & \text { 1. The reference base of decision is the amount of change of wealth; } \\ & \text { 2. People are risk-aversive for the investments in the range of profit-making } \\ & \text { and risk-preferring for the investments in the range of loss-making. }\end{aligned}$




$$
U(c, r, p)= \begin{cases}\left(a_{0}\right)^{p \ln r} & r \leq r^{*} \\ \left(a_{0}\right)^{p\left(r^{*} / r\right) \ln r^{*}} & r>r^{*}\end{cases}
$$

\subsubsection{The First Order Partial Derivative}

$$
\begin{gathered}
\partial U / \partial a_{0}= \begin{cases}p \ln r\left(a_{0}\right)^{p \ln r-1}>0 & r \leq r^{*} \\
p\left(r^{*} / r\right) \ln r^{*}\left(a_{0}\right)^{\left[p\left(r^{*} / r\right) \ln r^{*}\right]-1}>0 & r>r^{*}\end{cases} \\
\partial U / \partial p= \begin{cases}\left(a_{0}\right)^{p \ln r} \ln a_{0} \ln r>0 & r \leq r^{*} \\
\left(r^{*} / r\right)\left(a_{0}\right)^{p\left(r^{*} / r\right) \ln r^{*}} \ln a_{0} \ln r^{*}>0 & r>r^{*}\end{cases} \\
\partial U / \partial p= \begin{cases}\left(r^{*} / r\right)\left(a_{0}\right)^{p \ln r} \ln a_{0}>0 & r \leq r^{*} \\
-\left(p r^{*} / r^{2}\right)\left(a_{0}\right)^{p\left(r^{*} / r\right) \ln r^{*}} \ln a_{0} \ln r^{*}<0 & r>r^{*}\end{cases}
\end{gathered}
$$

\subsubsection{The Second Order Partial Derivative}

(1) if $r \leq r^{*}$, then

$$
\partial^{2} U / \partial r^{2}=\left(p / r^{2}\right)\left(p \ln a_{0}-1\right)\left(a_{0}\right)^{p \ln r} \ln a_{0} \quad r \leq r^{*}
$$

where when $\left(p \ln a_{0}-1\right)>0$, i.e. $a_{0}>\mathrm{e}^{1 / p} \partial^{2} U / \partial r^{2}>0$, the utility curve convexes downward; when $\left(p \ln a_{0}-1\right)<0$, i.e. $a_{0}<\mathrm{e}^{1 / p} \partial^{2} U / \partial r^{2}<0$, the utility curve concaves downward. Since only when the expected profit rate is more than 0 (that is, $(r p-c) / c>0$ or $\left.r / c=a_{0}\right)$ will an investor have the willingness to invest, naturally when $r \leq r^{*}$ and $1 / p<a_{0}<\mathrm{e}^{1 / p}$, the utility curve concaves downward; when $a_{0}>\mathrm{e}^{1 / p}$, the utility curve convexes downward. In general, when the income-cost ratio $a_{0} \in\left(1 / p, \mathrm{e}^{1 / p}\right)$, the utility curve concaves downward.

(2) if $r>r^{*}$, then

$$
\begin{aligned}
& \partial^{2} U / \partial r^{2} \\
& =\left(p r^{*} / r^{2}\right)\left(2+p r^{*} \ln a_{0} \ln r^{*} / r\right)\left(a_{0}\right)^{p\left(\frac{r^{*}}{r}\right) \ln r^{*}} \ln a_{0} \ln r^{*}>0 \quad r>r^{*}
\end{aligned}
$$

where when $r>r^{*}$, the utility curve convexes downward.

As for the cost of investment $c$, its partial effects under the constraint of the income-cost ratio are similar to those of investment income $r$. Table 2 summarizes the findings of partial effect analysis of the utility function based on the psychological endurance hypothesis.

\subsection{Matlab Checking Computation of the Partial Effects}

\subsubsection{The Impact on Utility of the Investment Success Rate}

The impacts on utility of the probability of investment success are examined under the conditions of, respectively, $r \leq r^{*}$ and $r>r^{*}$, by maintaining the income-cost ratio at $a_{0}=2$ and assuming the critical point of psychological endurance $r^{*}=100$. Figure 6 exhibits that for the situation with either $r \leq r^{*}$ or $r>r^{*}$, there exists a positive correlation between the investment success rate $P$ and utility $U$, giving the income-cost ratio constant. 
Table 2. The partial effects of relevant variables and parameters (constraint of $r / c=$ $\left.a_{0}>1 / p\right)$.

\begin{tabular}{lll}
\hline \multicolumn{1}{c}{ Variables and parameters } & \multicolumn{1}{c}{$\begin{array}{c}\text { Partial derivatives of } \\
\text { utility function }\end{array}$} & Partial effects on utility \\
\hline $\begin{array}{l}\text { Income-cost ratio } a_{0} \\
\text { Probability of investment } \\
\text { success } p\end{array}$ & $\partial U / \partial a_{0}>0$ & $U$ increases as $a_{0}$ increases \\
Income $r$ & $\partial U / \partial r>0$, if $r \leq r^{*}$ & $U$ increases as $p$ increases \\
& $\partial U / \partial r<0$, if $r>r^{*}$ & $U$ decreases as $r$ increases \\
Cost of invereases \\
\end{tabular}

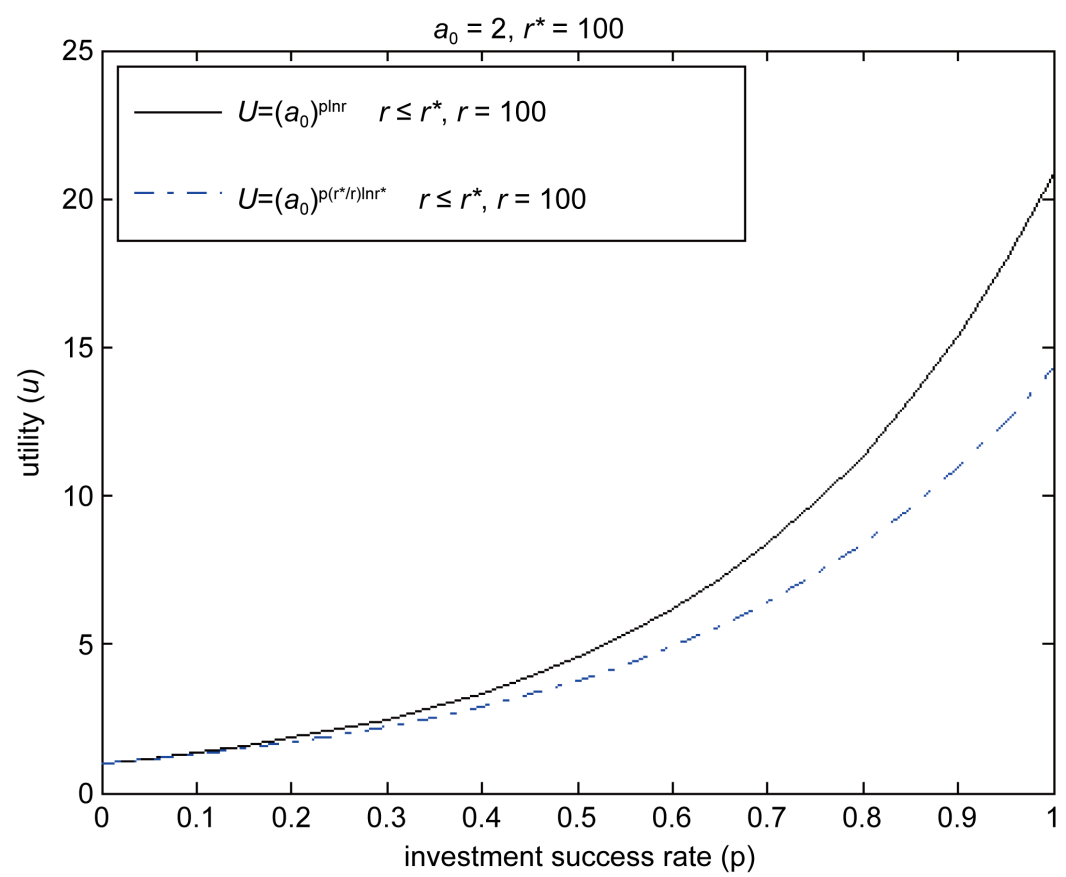

Figure 6. Impact of investment success rate on utility.

\subsubsection{The Impact on Utility of the Absolute Income Level}

The impact on utility of the absolute income level is examined by holding the income-cost ratio $r / c=a_{0}=4$, investment success rate $p=0.5$, and assuming the critical point of psychological endurance $r^{*}=200$. With the same income-cost ratio, the income and the cost of an investment have the same proportional change, so the impact on utility of absolute income level is consistent with that of absolute cost level. As demonstrated by Figure 7, under the same risk level (i.e. giving the investment success rate) and giving the income-cost ratio, the perceived investment value increases as the absolute income or cost level increases if the income is smaller than the critical point of psychological endurance; the perceived investment value decreases as the absolute income or cost level increases if the income surpasses the critical point of psychological endurance. 


\subsubsection{The Impact on Utility of the Income-Cost Ratio}

In order to discuss the impact on utility of the income-cost ratio, we first hold constant the probability of investment success $p=0.5$, and assume the critical point of psychological endurance as $r^{*}=100$. The different income-cost ratio levels are $a_{0}=3, a_{0}=4$, and $a_{0}=5$. The numerical results are displayed in Figure 8 and are in consistence with the points of psychological endurance hypothesis, that is, the investment value will increase as the investment return rate (or income-cost ratio) increases.

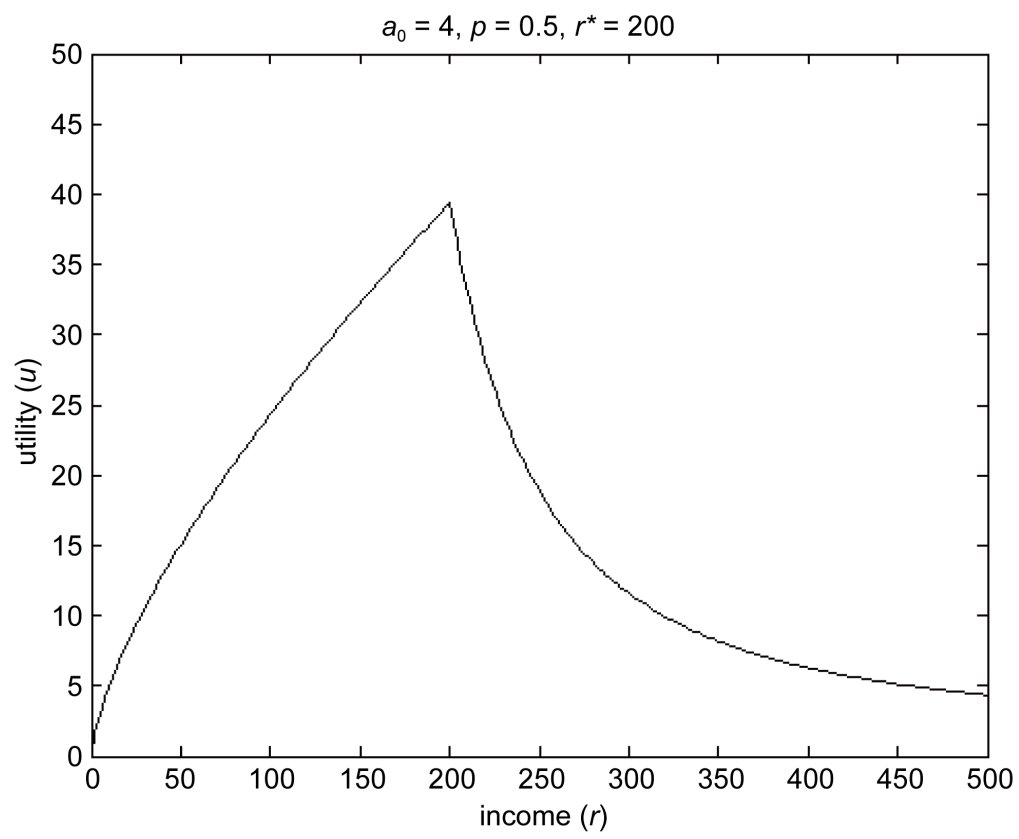

Figure 7. Impact on utility of absolute income level.

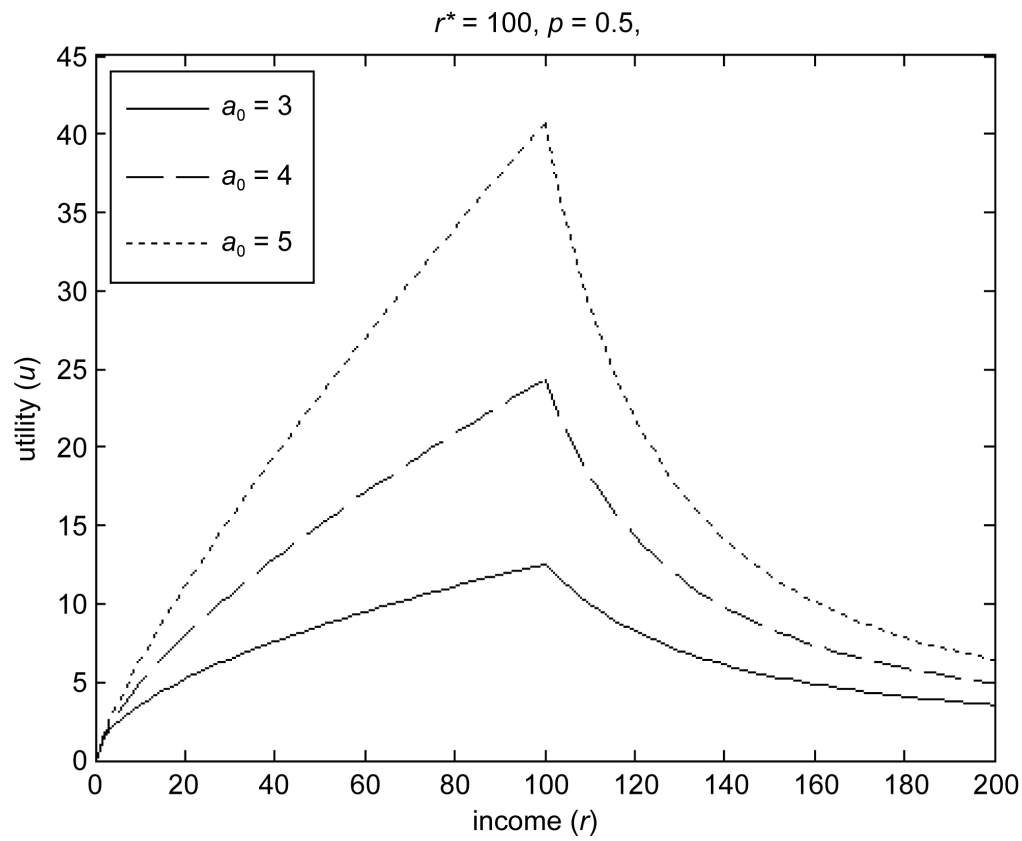

Figure 8. Impact on utility of the income-cost ratio. 


\subsection{The Attributes of the Indifference Curve of the Psychological Vulnerability Function}

Taking the reciprocal of the utility function, $u_{j}\left(c_{j}, r_{j}\right)$, of psychological endurance, we get the psychological vulnerability function $u_{j}^{-1}\left(c_{j}, r_{j}\right)$. From the attributes of $u_{j}\left(c_{j}, r_{j}\right)$, it is not difficult to infer that $u_{j}^{-1}\left(c_{j}, r_{j}\right)$ is a convex function like common production functions. For the convenience of analysis, we may utilize the Cobb-Douglas function to depict $u_{j}^{-1}\left(c_{j}, r_{j}\right)$ as in formula (10).

$$
U_{j}^{-1}\left(c_{j}, r_{j}\right)=R c_{j}^{\alpha} r_{j}^{1-\alpha}, \alpha \in(0,1), R \in(0,1)
$$

In formula (10), $R$ represents the level of social risk (accordingly $R^{-1}$ is the level of social security), $\alpha$ denotes the information-sharing cost elasticity of psychological vulnerability (meaning with $1 \%$ of increase of the cost of information sharing, the psychological vulnerability will rise by $\alpha \%$ ). By taking the reciprocal of formula (10) we get the expression of the utility function, $u_{j}\left(c_{j}, r_{j}\right)$, of psychological endurance as shown in formula (11).

$$
U_{j}\left(c_{j}, r_{j}\right)=R^{-1} c_{j}^{-\alpha} r_{j}^{-(1-\alpha)}
$$

It is not hard to infer from formula (10) that the psychological vulnerability function $u_{j}^{-1}\left(c_{j}, r_{j}\right)$ has the attributes of indifference curve in Figure 9.

In Figure 9, the three indifference curves $u_{j}^{-1}(1), u_{j}^{-1}(2), u_{j}^{-1}(3)$ denotes respectively low, intermediate, and high vulnerability isoline, and the partingline of $45^{\circ}$ (dotted line) is the equal-value line of income and cost. In the region above the parting-line the income is bigger than the cost, where information sharing is possible; whereas in the region below the parting-line the income is smaller than the cost, where information sharing is impossible.

\section{The Supply Chain Information Sharing Model Based on the Psychological Endurance Utility Function}

\subsection{A General Structure of Supply Chain}

Many literatures classify the modes of supply chains into two-stage supply chain

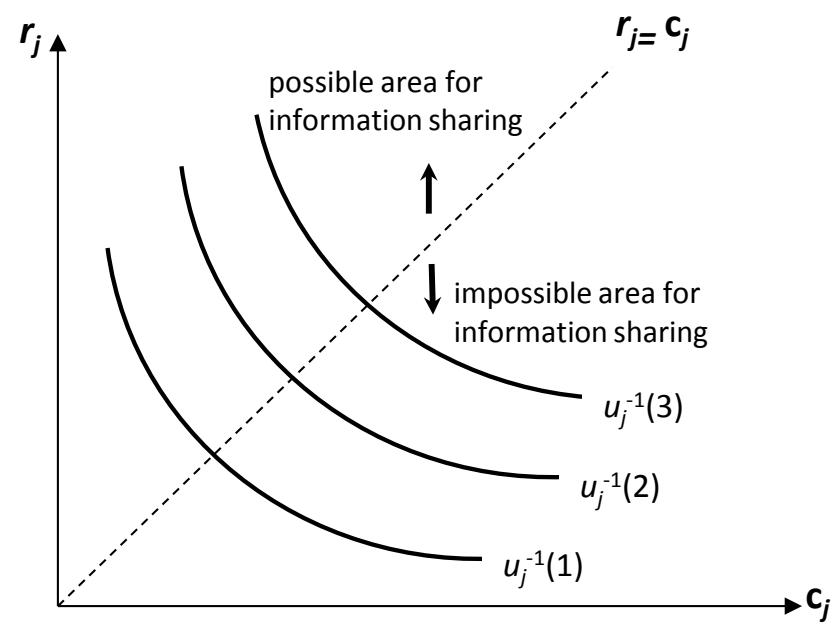

Figure 9. Indifference curve out of psychological vulnerability function $u_{j}^{-1}$. 
and three-stage supply chain. Li (2002) built a two-stage supply chain comprising one producer and $n$ distributors. Zhong (2010) established a three-stage supply chain consisting of producers, distributors and customers. In this paper, a general structure of supply chain is constructed that has a leading enterprise functioning as the center and includes some upstream suppliers and some downstream customers as demonstrated in Figure 10.

\subsection{The Value Index of Information Sharing for Individual Enterprises}

If the value index of information sharing for enterprise $j$ is denoted by $M_{j}$, and $u_{j}\left(c_{j}, r_{j}\right)$ represents that enterprise's utility function of psychological endurance (accordingly $u_{j}^{-1}\left(c_{j}, r_{j}\right)$ is the psychological vulnerability function of that enterprise), then $M_{j}$ can be expressed by formula (12) in light of the psychological endurance hypothesis.

$$
M_{j}=\left(r_{j} P_{j} / c_{j}\right)^{u_{j}\left(c_{j}, r_{j}\right)}
$$

In formula (12), the connotation of base number $\left(r_{j} P_{j} / c_{j}\right)$ is that the value of information sharing accruing to one individual enterprise is determined by that enterprise's income-cost ratio resulting from information sharing, and the power $u_{j}\left(c_{j}, r_{j}\right)$ means that giving the income-cost ratio, the value of information sharing accruing to one individual enterprise decreases with the increase of absolute income level resulting from information sharing, or decreases with the decrease of psychological endurance resulting from that enterprise's providing information for sharing. In this situation, the utility function of psychological endurance, $u_{j}\left(c_{j}, r_{j}\right)$, is a decreasing function with respect to both the cost of information sharing $c_{j}$ and the income of information sharing $r_{p}$ subjecting to the constraints in the formulas from (13) to (15):

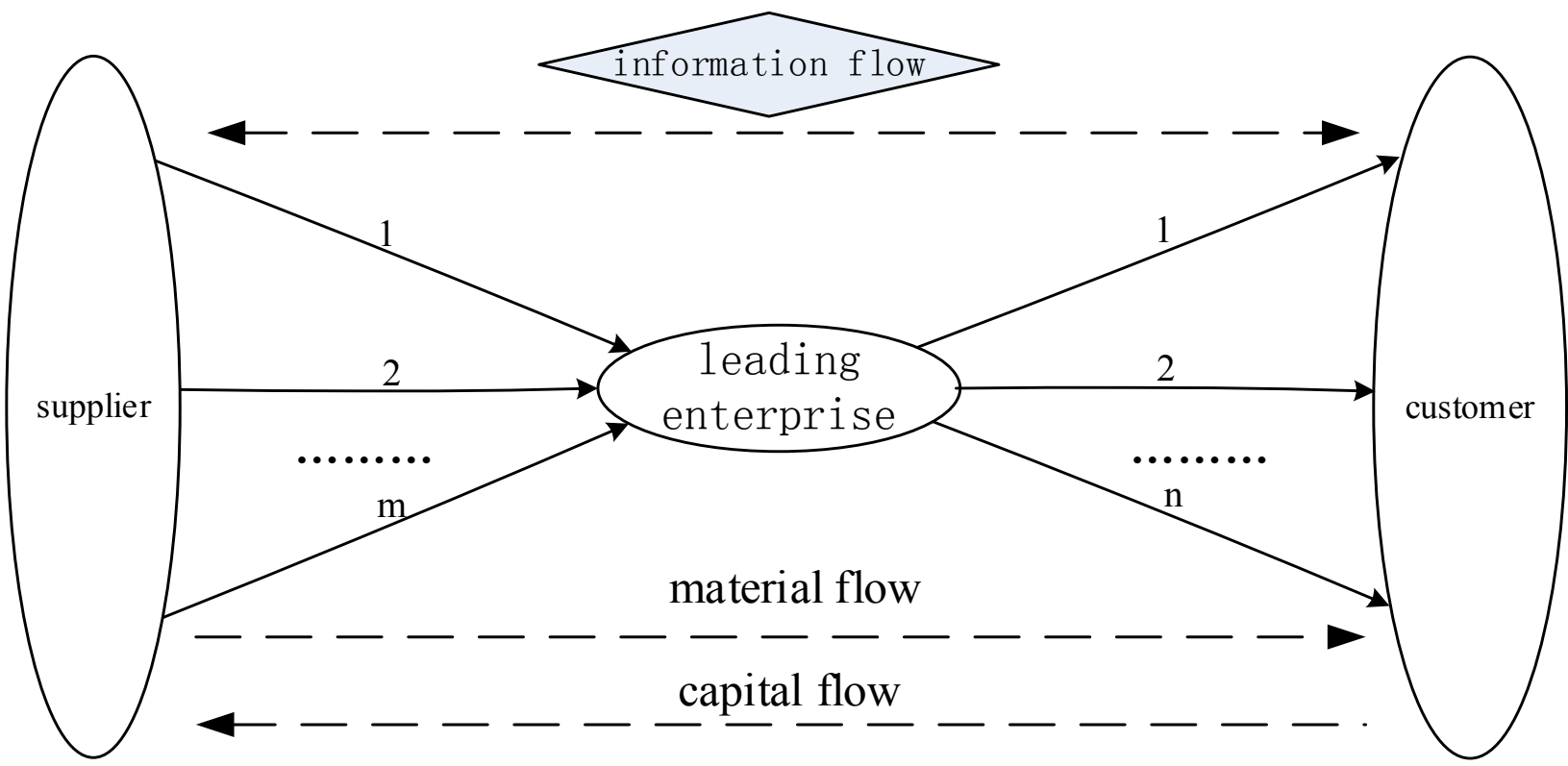

Figure 10. General structure of supply chain. 


$$
\begin{aligned}
& \frac{\partial u_{j}}{\partial u_{j}}<0 \\
& \frac{\partial u_{j}}{\partial r_{j}}<0 \\
& \nabla^{2} u_{j} \text { positive semi-definite }
\end{aligned}
$$

\subsection{The Determinants of the Value Index of Information Sharing}

Substituting the expression of utility function of psychological endurance $u_{j}\left(c_{j}, r_{j}\right)$ into the definition formula (12), we obtain formula (16).

$$
M_{j}=\left(P_{j} r_{j} / c_{j}\right)^{R^{-1} c_{j}^{-\alpha} r_{j}^{-(1-\alpha)}}
$$

Take the partial derivation of formula (16) with respect to the variables and parameters subjective to the optimal condition $K_{j} \geq P_{j}$ of the value index of information sharing, and the results are presented as follows:

(1) taking partial derivative of $M_{j}$ against $P_{p}$ the result is $\partial M_{j} / \partial P_{j} \geq 0$, indicating that $M_{j}$ increases as $P_{j}$ increases;

(2) taking partial derivative of $M_{j}$ against $\alpha$, the information-sharing cost elasticity of psychological vulnerability, the result is $\partial M_{j} / \partial \alpha \leq 0$, indicating that $M_{j}$ increases as $\alpha$ decreases;

(3) taking partial derivative of $M_{j}$ against the social risk level $R$, the result is $\partial M_{j} / \partial R \leq 0$, indicating that $M_{j}$ increases as $R$ decreases;

(4) taking partial derivative of $M_{j}$ against the cost of information sharing $c_{p}$ the result is $\partial M_{j} / \partial c_{j} \leq 0$, indicating that $M_{j}$ increases as $c_{j}$ decreases;

(5) taking partial derivative of $M_{j}$ against the income from information sharing $r_{p}$ the result is $\partial M_{j} / \partial r_{j} \leq 0$ when $K_{j} \leq P_{j} \mathrm{e}^{-(1 / 1-\alpha)}$, indicating that $M_{j}$ increases as $r_{j}$ decreases; while when $K_{j}>P_{j} \mathrm{e}^{-(1 / 1-\alpha)}$, the result is $\partial M_{j} / \partial r_{j}>0$, indicating that $M_{j}$ increases as $r_{j}$ increases (Table 3 summarizes all the above results).

\subsection{Supply Chain Information Sharing Model}

For a supply chain made of Jenterprises to realize overall information sharing as

Table 3. Partial impacts on the value index of information sharing of relevant variables and parameters (with the constraint of $P_{j} \geq$ $\left.K_{j}\right)$.

\begin{tabular}{llc}
\hline \multicolumn{1}{c}{ Variables and parameters } & $\begin{array}{c}\text { Partial derivatives of the value } \\
\text { Index of information sharing }\end{array}$ & $\begin{array}{c}\text { Partial effects on the value } \\
\text { index of information }\end{array}$ \\
\hline Success rate of information sharing $P_{j}$ & $\partial M_{j} / \partial P_{j} \geq 0$ & $M_{j}$ increases as $P_{j}$ increases \\
Information-sharing cost elasticity of psychological vulnerability $\alpha$ & $\partial M_{j} / \partial \alpha \leq 0$ & $M_{j}$ increases as $\alpha$ decreases \\
Social risk level $R$ & $\partial M_{j} / \partial R \leq 0$ & $M_{j}$ increases as $R$ decreases \\
Cost of information sharing $c_{j}$ & $\partial M_{j} / \partial c_{j} \leq 0$ & $M_{j}$ increases as $c_{j}$ decreases \\
Income from information sharing $r_{j}$ & $\partial M_{j} / \partial r_{j} \leq 0$, when $K_{j} \leq P_{j} \mathrm{e}^{-(1 / 1-\alpha)}$ & $M_{j}$ increases as $r_{j}$ decreases \\
& $\partial M_{j} / \partial r_{j}>0$, when $K_{j}>P_{j} \mathrm{e}^{-(1 / 1-\alpha)}$ & $M_{j}$ increases as $r_{j}$ increases \\
\hline
\end{tabular}


a whole, each and every enterprise in the chain must provide adequate and sufficient information for sharing. In contrary, if any enterprise of the chain offers inadequate and insufficient information for sharing, the information sharing of the supply chain fails as a whole. This is in fact the manifestation of the shorter-board effect in information sharing. To achieve the information sharing of the whole supply chain, the value of information sharing of the shorter-board enterprise must be raised so that every enterprise can reach the goal of providing required information for sharing. Following this logicality, we may construct the shorter-board optimization model of supply chain information sharing as indicated by formula (17).

$$
\begin{aligned}
& \operatorname{Max} \min M_{j}=\left(r_{j} P_{j} / c_{j}\right)^{u_{j}\left(c_{j}, r_{j}\right)} \\
& \text { s.t. } P_{j} \geq K_{j}, K_{j}=\left(c_{j} / r_{j}\right) \\
& c_{j} \geq 0, r_{j} \geq 0
\end{aligned}
$$

In formula (17), $K_{j}$ is the cost per unit of income, also the reciprocal of the income per unit of cost. The meaning of formula (17) is to raise unceasingly the value index of information sharing of the shorter-board enterprise to eventually make true the information sharing of the supply chain as a whole.

\subsection{The Iterative Algorithm for the Shorter-Board Optimization Model of Supply Chain Information Sharing}

Suppose the critical point of the value index of information sharing is $M^{*}$, which means only when the shorter-board enterprise's value index of information sharing gets to the critical point, can the overall information sharing of the whole supply chain be materialized. In accordance with the shorter-board effect principle, the optimizational objective is to enable the enterprises with the lowest value index of information sharing to achieve $M^{*}$, i.e. $\min \left(M_{j}\right) \geq M^{*}(j \in J)$. Thus Figure 11 exhibits the iterative algorithm for the shorter-board optimization model of supply chain information sharing.

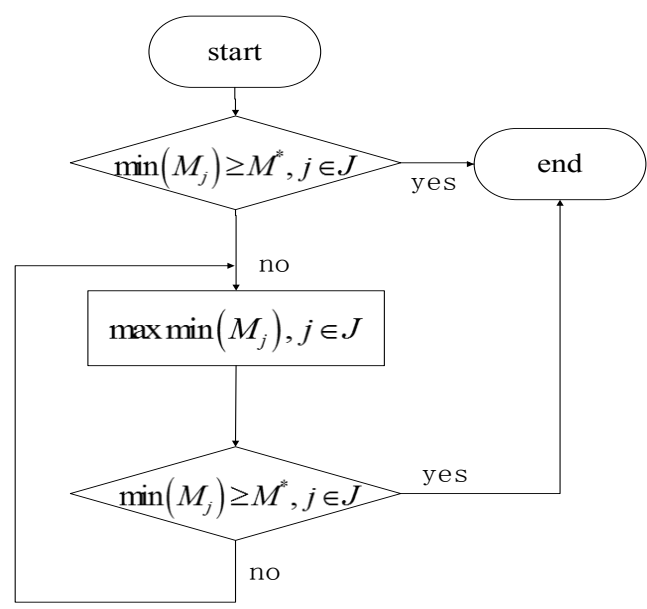

Figure 11. Iterative algorithm for shorter-board optimization model of supply chain information sharing. 


\section{Conclusions and Implications}

Having analyzed the defects of the expected utility theory and of the prospect theory, this paper has put forward the hypothesis of psychological endurance and accordingly constructed the decision utility function based on the hypothesis, which have improved the traditional theories of decisions with risks in three aspects. First of all, the income-cost ratio is introduced into the set of constraints of the value of an investment, which singles out the decisive role played by investment return rate or profit rate and believes that the value of an investment is mainly determined by investment return rate (or income-cost ratio). Second, having found out the fact that the value of an investment changes with the change of investor's psychological endurance, we have introduced innovatively the concept of the critical point of psychological endurance, revealing that the investment behaviors on the left and right side of this critical point demonstrate totally different characteristics. Thirdly, further analyzing the decision utility function based on the hypothesis of psychological endurance shows that there exist positive relationships between the value of an investment and both the investment success rate and the investment return rate (i.e. the income-cost ratio), and that the relation between the value of an investment and the absolute income (or cost) level depends on the location of the critical point of psychological endurance. According to the above findings, there are three options to upgrade the value of an investment (or investing willingness): by increasing the investment success rate, by increasing the investment return rate (i.e. the income-cost ratio), or by exercising the psychological endurance of investors so as to move outward the location of investors' critical point of psychological endurance.

Finally, on the basis of our psychological endurance hypothesis, the shorterboard optimization model of supply chain information sharing is constructed with the decision variable of the value index of information sharing. The fundamental conception of this model is to raise unceasingly the value index of information sharing of the shorter-board enterprise to eventually materialize the information sharing of the supply chain as a whole. Consequently, there are four pathways to improve supply chain information sharing: to increase the success rate of information sharing, to lower the information-sharing cost elasticity of psychological vulnerability, to decrease the social risk level, and to reduce the cost of information sharing.

\section{Acknowledgements}

We thank kindly for the funding of this research by The Major Project Grant under The National Soft Science Research Program of China: Research on the Major Issues Regarding Promoting Balanced Urban and Rural Development through Informatization (2011GXS1D003).

\section{References}

Bell, D. E. (1985). Disappointment in Decision Making under Uncertainty. Operations Research, 33, 1-27. https://doi.org/10.1287/opre.33.1.1 
Cabantous, L., \& Cedric, D. (2004). Is Probability Weighting Sensitive to the Quality of Probabilistic Information? An Experimental Investigation on the Impact of Vagueness and Conflict on Probabilistic Weighting Functions. 2004 North American Regional Meeting, Tucson, University of Strasbourg, France.

Chen, C., \& Miao, L. (2010). Information Sharing Incentive under the Obligation of the Supply Chain Flexibility Contract. Contemporary Economy and Management, 32, 23 28.

Ge, Y., Yang, J. B., \& Spring, M. (2004). System Dynamics Modeling for Supply-Chain Management: A Case Study on a Supermarket Chain in the UK. International Transactions in Operational Research, 11, 495-509. https://doi.org/10.1111/j.1475-3995.2004.00473.x

Kahneman, D., \& Tversky, A. (1979). Prospect Theory: An Analysis of Decision Making under Risk. Econometrica, 47, 263-292. https://doi.org/10.2307/1914185

Li, L. (2002). Information Sharing in a Supply Chain with Horizontal Competition. Management Science, 48, 1196-1212. https://doi.org/10.1287/mnsc.48.9.1196.177

Lin, Z., \& Tsao, D. B. (2006). On the Evaluation of Downstream Information Sharing. Journal of Japan Industrial Management Association, 56, 413-420.

Loomes, G., \& Sugden, R. (1986). Disappointment and Dynamic Consistency in Choice under Uncertainty. Review of Economic Studies, 53, 271-282. https://doi.org/10.2307/2297651

Ma, X., Zhang, L., \& Tian, P. (2001). Information Sharing Incentive in Supply Chain. Chinese Journal of Management Science, 9, 19-24.

Mellers, B. A. (2000). Choice and the Relative Pleasure of Consequences. Psychological Bulletin, 126, 910-924. https://doi.org/10.1037/0033-2909.126.6.910

Mishra, B. K., Raghunathan, S., \& Yue, X. (2007). Information Sharing in Supply Chains: Incentives for Information Distortion. IIE Transactions, 39, 863-877.

https://doi.org/10.1080/07408170601019460

Mukhopadhyay, S. K., Yue, X. H., \& Zhu, X. W. (2011). A Stackelberg Model of Pricing of Complementary Goods under Information Asymmetry. International Journal of Production Economics, 134, 424-433.

Simon, H. A. (1956). Rational Choice and the Structure of the Environment. Psychological Review, 63, 129-138. https://doi.org/10.1037/h0042769

Sun, K., \& Liu, R. (2013). Inter-Organizational Information Sharing Strategy Choice Based on Information Processing Theory. Chinese Journal of Management, 10, 293 298.

Tversky, A., \& Kahneman, D. (1992). Advances in Prospect Theory: Cumulative Representation of Uncertainty. Journal of Risk and Uncertainty, 5, 297-323. https://doi.org/10.1007/BF00122574

von Neumann, J., \& Morgenstern, O. (1944). The Theory of Games and Economic Behavior. Princeton, NJ: Princeton University Press.

Wang, L., Lu, Q., \& Shen, X. (2013). How Can Emotional Arousal Affect Decisions under Uncertainty? From the Perspective of Decision Preferences. Journal of Industrial Engineering and Engineering Management, 27, 16-21.

Wu, G., \& Gonzalez, R. (1996). Curvature of the Probability Weighting Function. Management Science, 42, 1676-1690. https://doi.org/10.1287/mnsc.42.12.1676

Xiao, M. (2011). Research on the Effect of Emotional Conflict on Decision-Making under Uncertainty. Chongqing: Southwest University.

Ye, F., Chen, X., \& Lin, Q. (2012). Analysis of Supply Chain's Demand Information 
Sharing Values Based on Decision-Maker's Risk Aversion Characteristics. Journal of Industrial Engineering and Engineering Management, 26, 176-183, 196.

Zhang, H. (2002). Vertical Information Exchange in a Supply Chain with Duopoly Retailers. Production and Operations Management, 11, 531-546. https://doi.org/10.1111/j.1937-5956.2002.tb00476.x

Zhang, Y., \& Chen, J. (2004). Study Based on Stackelberg Game about the Information Sharing Coordination in Supply Chain. Journal of Industrial Engineering and Engineering Management, No. 3, 118-120.

Zhang, Z., \& Zhou, Y. (2004). Cooperative Game Analysis of Stakeholders' Information Sharing in Supply Chain. Science and Technology Management Research, 24, 114-116.

Zhong, Z. (2010). Research on Supply Chain Information Sharing Model and Its Optimization. Chengdu: Southwest Jiaotong University.

Zhou, X., \& Ma, F. (2010). An Incentive Model of Information Sharing in Supply Chain with Demand Uncertainty. Journal of Industrial Engineering and Engineering Management, No. 4, 122-126.

Submit or recommend next manuscript to SCIRP and we will provide best service for you:

Accepting pre-submission inquiries through Email, Facebook, LinkedIn, Twitter, etc. A wide selection of journals (inclusive of 9 subjects, more than 200 journals)

Providing 24-hour high-quality service

User-friendly online submission system

Fair and swift peer-review system

Efficient typesetting and proofreading procedure

Display of the result of downloads and visits, as well as the number of cited articles

Maximum dissemination of your research work

Submit your manuscript at: http://papersubmission.scirp.org/

Or contact jifm@scirp.org 